ARQGA/1145

\title{
AVALIAÇÃO DAS ADERÊNCIAS PÓS-OPERATÓRIAS EM RATOS SUBMETIDOS A PERITONIOSTOMIA COM TELA DE POLIPROPILENO ASSOCIADA À NITROFURAZONA
}

\author{
Augusto DIOGO-FILHO, Bárbara Cunha Mello LAZARINI, Floriano VIEIRA-JUNYOR, \\ Gisele Juliana SILVA e Heitor Luiz GOMES
}

RESUMO - Racional - Lesões peritoniais, comuns no per e pós-operatório, levam à formação de aderências, cuja incidência aumenta ainda mais com o uso de telas de polipropileno. A nitrofurazona é uma substância que acelera o processo de cicatrização e, devido a isso, cogitouse a possibilidade de uma ação sobre as aderências peritoniais. Objetivo - Avaliar as aderências pós-operatórias em ratos submetidos a peritoniostomia com fixação de tela de polipropileno associada a nitrofurazona. Material e Métodos - Utilizaram-se 33 ratos Wistar, divididos em 3 grupos de 11 animais, sendo no grupo I realizado laparotomia com exposição da cavidade ao ar ambiente e posterior laparorrafia; no grupo II, ressecção de fragmento da parede abdominal com fixação de tela de polipropileno no espaço e no grupo III, procedimento semelhante ao do grupo II, porém com tela embebida em nitrofurazona. Após 45 dias foram sacrificados e necropsiados. Resultados - Dos animais do grupo I, sete não tiveram aderências (grau 0), dois tiveram aderências de grau 1 e dois de grau 2. No grupo II, 1 foi classificado como grau 3 e 10 como grau 4 . No grupo III, um foi de grau 0, oito de grau 3 e um de grau 4 (um animal foi a óbito antes de 45 dias). Todas as aderências encontradas envolveram parede abdominal; 10 animais tiveram aderências envolvendo apenas o omento (grupo $\mathrm{I}=4$; grupo $\mathrm{II}=1$ e grupo III = 5); 11 animais tiveram aderências envolvendo o omento, as alças intestinais e outros órgãos abdominais, sendo 10 do grupo II e um do grupo III; três animais tiveram aderências envolvendo apenas alças intestinais, sendo todos do grupo III. Dos 14 animais que tiveram aderências envolvendo as alças intestinais, 10 eram do grupo II ( 9 com mais de um ponto) e 4 do grupo III ( 3 com somente um ponto de fixação). Conclusão - O uso de nitrofurazona associado à tela de polipropileno não reduziu significativamente a incidência de aderências pós-operatórias em ratos, porém diminuiu a intensidade e gravidade dessas aderências.

DESCRITORES - Peritônio, cirurgia. Aderências. Telas cirúrgicas. Nitrofurazona. Ratos.

\section{INTRODUÇÃO}

Estímulos traumáticos ao peritônio, como isquemia tecidual, infecção e reação a corpos estranhos, processos comuns no per e pós-operatório, predispõem a formação de aderências nessa serosa ${ }^{(18)}$.

A lesão peritonial decorrente desses estímulos nocivos suscita uma reação inflamatória serossangüínea que leva a depósitos de fibrina. Ativadores locais de plasminogênio iniciam a lise dos filamentos de fibrina, em geral, dentro de 3 dias de sua formação. A metamorfose de células mesodérmicas regenera uma camada única de mesotélio novo em apenas 5 dias após a lesão. Por outro lado, fibrinólise inadequada permite que a proliferação de fibroblastos produza aderências fibrosas. Cogita-se a possibilidade da relação direta entre a presença de mastócitos no processo inflamatório e o início do processo adesivo. Acredita-se que o mastócito se une aos fibroblastos intestinais, desencadeando sua proliferação, o que já foi comprovado in vitro e em modelos experimentais ${ }^{(28)}$.
Aderência pós-operatória é a causa mais prevalente de obstrução aguda e recidivante de intestino delgado e um infortúnio persistente após cirurgia abdominal e pélvica. As medidas profiláticas para sua redução visam diminuir a intensidade da resposta inflamatória e a coagulabilidade e impedir o contato prolongado entre superfícies justapostas, através de efeitos siliconizantes ${ }^{(10)}$.

Há divergências em relação à profilaxia das aderências peritoniais. Substâncias como a rifamicina, o polímero da glicose de alto peso molecular (dextrano 70 - Hyskon), a heparina e a prometazina já foram testadas, sendo consideradas eficazes em alguns estudos e ineficazes em outros, podendo até potencializar o processo adesivo em alguns $\operatorname{casos}^{(2,6,9,22)}$.

Vários estudos em animais foram realizados no intuito de se aprimorar tal profilaxia, apontando menor incidência de aderências com o uso de membrana de sódio-hialuronidase/ carboximetilcelulose e azul de metileno. Porém, ainda não há relatos de sua eficácia em humanos ${ }^{(11,13,14,18)}$.

Departamento de Cirurgia, Faculdade de Medicina da Universidade Federal de Uberlândia.

Endereço para correspondência: Dr. Augusto Diogo Filho - Av. Levino de Souza, 1755 - Umuarama - 38405-322 - Uberlândia, MG. E-mail: diogofilho@netsite.com.br 
O polipropileno é um material sintético que produz pouca reação tecidual e possui boa resistência tênsil, resistência esta que é mantida por vários anos após seu uso em organismos vivos. Outros materiais, como tela à base de poliéster, foram propostos e apesar da diminuição nos índices de aderências, estes se mostraram inferiores pela menor resistência tênsil ${ }^{(8,27)}$.

A tela de polipropileno é freqüentemente usada em peritoniostomias e no reparo de hérnias abdominais. A peritoniostomia tem sido recomendada para condições nas quais múltiplas intervenções são necessárias para controlar uma infecção intra-abdominal e o uso associado da tela evita a hipertensão abdominal, facilita a reintervenção, previne a evisceração e minimiza o dano da parede abdominal ${ }^{(17,21)}$.

As principais reações teciduais desencadeadas pela tela de polipropileno são: reação granulomatosa do tipo corpo estranho, reação inflamatória crônica e fibrose exacerbada ${ }^{(17)}$.

Após algumas semanas de sua fixação como prótese de parede abdominal, o tecido de granulação, oriundo do grande omento e das margens da ferida operatória, permeia as malhas da tela incorporando todo o material sintético. Nessa ocasião, pode-se deixar a ferida prosseguir a sua cicatrização por segunda intenção( ${ }^{(5)}$.

Entretanto, quando em contato com os órgãos intra-abdominais, a tela é associada ao aumento da incidência de aderências ${ }^{(4)}$.

O mecanismo de aderência atribuído a esse tipo de tela é o preenchimento das irregularidades de sua superfície por grande extensão de tecido adiposo, além do mecanismo inflamatório associado à lesão cirúrgica ${ }^{(26)}$.

A principal complicação da formação de aderências devido ao uso de material sintético (telas) em peritoniostomias é o aparecimento de fístulas, seroma e obstrução intestinal ${ }^{(3)}$.

A nitrofurazona, da família dos furanos, é um agente bactericida que se acumula no tecido adiposo de animais e interfere nas fases precoces do ciclo de Krebs, inibindo a formação anaeróbica da acetil-coenzima A, do piruvato ao oxalato e bloqueando o metabolismo glicídico das células bacterianas. Tem limitada interação com os constituintes do sangue e do pus, tendo boa penetração em fissuras. Não sofre absorção significativa através da pele íntegra ou queimada, nem a partir de membranas mucosas, o que dá suporte ao seu uso tópico. Gera dermatite de contato do tipo pustular em apenas $0,5 \%$ a $2,0 \%$ dos casos. Pode interferir no fechamento de ferimentos, atuando na redução do tecido de granulação ${ }^{(1,12)}$.

Alguns estudos relacionam a nitrofurazona à carcinogênese em modelos experimentais. Há relatos de efeitos neoplásicos em órgãos reprodutivos de ratos, porém esse processo ainda não foi observado em seres humanos ${ }^{(23,24)}$.

Estudo experimental mostrou que o emprego de um derivado da nitrofurazona diminuiu o grau de aderências peritoniais em cães, provavelmente por interferência no processo cicatricial ${ }^{(20)}$.

\section{Objetivo}

Avaliar as aderências peritoniais em ratos submetidos a peritoniostomia com uso de tela de polipropileno associada a nitrofurazona.

\section{MATERIAIS E MÉTODOS}

Para o desenvolvimento deste trabalho foram utilizados 33 ratos da linhagem Wistar, adultos jovens, aparentemente sadios, fornecidos pelo Laboratório de Técnica Operatória da Universidade Federal de Uberlândia. As intervenções cirúrgicas foram realizadas segundo as normas presentes no Guide for the care and use of laboratory animals ${ }^{(7)}$.
Os animais, após pesagem, foram divididos aleatoriamente em três grupos com 11 ratos cada, assim distribuídos:

grupo I ("controle"): realizou-se abertura da pele e linha alba, incluindo o peritônio, numa extensão de aproximadamente 5,0 $\mathrm{cm}$. A cavidade abdominal ficou exposta ao ar ambiente por 5 minutos. Procedeu-se à laparorrafia com fio de poligalactina 6-0, atraumático, agulhado, com pontos separados. A pele foi fechada com mononylon 3-0, com pontos simples separados. Fez-se curativo tipo "tie over", com gaze suturada à pele do animal também com mononylon 3-0;

grupo II ("tela"): fez-se a ressecção de um fragmento de toda a espessura da parede abdominal de aproximadamente 1,5 x $5,0 \mathrm{~cm}$. Procedeu-se peritoniostomia com tela de polipropileno fixada às bordas da parede abdominal com fio de poligalactina 6-0, agulhado, atraumático, com pontos separados. O curativo foi feito da mesma forma que no grupo I;

grupo III ("tela + nitrofurazona"): procedeu-se identicamente ao grupo II, entretanto utilizando tela de polipropileno embebida em nitrofurazona em solução a $0,2 \%\left(\right.$ Furacin $\left.^{\circledR}\right)$.

Todos os procedimentos foram acompanhados por técnico especializado e realizados sob técnica asséptica e anestesia com cloridrato de cetamina $\left(\operatorname{Ketalar}^{\circledR}\right)$ a $5 \%$, na dose de $0,1 \mathrm{~mL} / 100 \mathrm{~g}$ de peso, via intramuscular ${ }^{(16)}$. Após a anestesia, realizou-se tonsura da parte ventral do abdome do rato, fixação à prancha cirúrgica em decúbito dorsal horizontal e identificação, através de números marcados com pincel em suas caudas. $\mathrm{O}$ ato operatório foi iniciado após o animal atingir plano anestésico, testado pelo reflexo de retirada da pata em resposta ao estímulo doloroso.

$\mathrm{O}$ experimento foi seqüencial, atingindo o total de 11 animais por grupo. A cada dia de trabalho, eram realizados procedimentos em números iguais de animais para cada grupo.

Foram oferecidos água e ração ad libidum e, nos animais do grupo III, diariamente aplicou-se nitrofurazona em solução a $0,2 \%$ (Furacin $\left.{ }^{\circledR}\right)$ sobre o curativo.

Com tempo mínimo de 45 dias, os animais foram novamente pesados e sacrificados. Após injeção intramuscular de uma dose letal de cloridrato de cetamina $\left(\operatorname{Ketalar}^{\circledR}\right)$, procedeu-se à necropsia através de uma ressecção ampla da parede abdominal, à forma de um retângulo, procurando-se incluir, com margem de segurança, todo o local envolvido no procedimento cirúrgico anteriormente realizado. Com isso, avaliou-se a presença e intensidade de aderências entre os órgãos abdominais e o local da cicatriz cirúrgica, entre alças intestinais e entre o peritônio visceral e a tela. Investigou-se também a presença de fístulas entéricas.

Foi usado para critério de avaliação a classificação proposta por OLIVEIRA et al. ${ }^{(20)}$, porém com modificações: grau 0 - ausência de aderências; grau 1 - número reduzido de aderências, de caráter fibrinoso, facilmente desfeitas pela manipulação; grau 2 - aderências firmes, resistentes à manipulação, entre alças intestinais, porém não envolvendo parede abdominal; grau 3 - aderências firmes, resistentes à manipulação, entre a parede abdominal e um órgão ou estrutura; grau 4 - aderências firmes, resistentes à manipulação, entre a parede abdominal e mais de um órgão ou estrutura; grau 5 - aderências firmes, resistentes à manipulação, entre alças e entre alças e a parede abdominal, com fístula entérica.

Avaliou-se, também, a presença de evisceração, deiscência e obstrução intestinal com distensão abdominal e parada da eliminação de fezes. 
A análise estatística foi realizada com métodos apropriados para cada variável em estudo (análise de variância, teste $t$ e teste do qui-quadrado), sendo as diferenças consideradas significativas para $P<0,05$.

\section{RESULTADOS}

Dos 33 animais, 1 foi a óbito no $6^{\circ}$ dia de pós-operatório. $\mathrm{O}$ animal pertencia ao grupo III, teve como causa mortis hemorragia e foi excluído da análise.

Os pesos dos animais no pré-operatório e sua distribuição por grupos estão apresentados na Tabela 1.

TABELA 1 - Peso em gramas dos animais por grupo no pré-operatório

\begin{tabular}{lcccc}
\hline Peso $(\mathrm{g})$ & Grupo I & Grupo II & Grupo III & TOTAL \\
\hline $235 \neg 265$ & 4 & 1 & 2 & 7 \\
$265 \neg 295$ & 2 & 5 & 4 & 11 \\
$295 \neg 325$ & 3 & 4 & 3 & 10 \\
$325 \neg 355$ & 1 & 0 & 2 & 3 \\
$355 \neg 385$ & 0 & 1 & 0 & 1 \\
$385 \neg 415$ & 1 & 0 & 0 & 1 \\
\hline TOTAL & 11 & 11 & 11 & 33 \\
\hline
\end{tabular}

Os animais dos grupos I, II e III apresentavam como média de peso 293,64 g, 296,37 g e 293,64 g, respectivamente, numa média total de 294,54 g. Na comparação entre as médias dos grupos a análise de variância mostrou $\mathrm{F}(3,32)=0,35(P>0,05)$.

No dia da necropsia, os animais foram novamente pesados. A distribuição dos animais por peso e por grupo pode ser vista na Tabela 2 .

TABELA 2 - Peso em gramas dos animais por grupo no dia da necropsia

\begin{tabular}{lcccc}
\hline Peso $(\mathrm{g})$ & Grupo I & Grupo II & Grupo III & TOTAL \\
\hline $235 \neg 265$ & 3 & 1 & 5 & 9 \\
$265 \neg 295$ & 3 & 5 & 0 & 8 \\
$295 \neg 325$ & 2 & 4 & 3 & 9 \\
$325 \neg 355$ & 2 & 0 & 2 & 4 \\
$355 \neg 385$ & 0 & 0 & 0 & 0 \\
$385 \neg 415$ & 1 & 1 & 0 & 2 \\
\hline TOTAL & 11 & 11 & $10^{*}$ & 32
\end{tabular}

*Um animal do grupo III foi a óbito antes do tempo mínimo para necropsia.

Os grupos I, II e III apresentaram ao final do experimento médias de peso de 299,09 g, 299,09 g e 286,00 g, respectivamente, numa média total de $295,00 \mathrm{~g}$. A análise de variância entre as médias encontradas mostrou $\mathrm{F}(3,33)=0,18(P>0,05)$.

Analisando-se as médias de peso dos grupos antes e depois do experimento, pelo teste $t$, encontra-se $t(4,30)=2,24(P>0,05)$.

A média de tempo entre o procedimento cirúrgico e o sacrifício dos animais por grupo foram semelhantes, já que tanto um quanto o outro foram realizados com pelo menos um animal de cada grupo por dia.

As aderências peritoniais encontradas foram avaliadas e classificadas por graus, como se pode ver na Tabela 3.

TABELA 3-Classificação em graus das aderências peritoniais nos animais por grupos

\begin{tabular}{lcccc}
\hline & Grupo I & Grupo II & Grupo III & TOTAL \\
\hline Grau 0 & 7 & 0 & 1 & 8 \\
Grau 1 & 2 & 0 & 0 & 2 \\
Grau 2 & 0 & 0 & 0 & 0 \\
Grau 3 & 2 & 1 & 8 & 11 \\
Grau 4 & 0 & 10 & 1 & 11 \\
Grau 5 & 0 & 0 & 0 & 0 \\
\hline TOTAL & 11 & 11 & 10 & 32 \\
\hline
\end{tabular}

Como se pôde observar, nenhum animal apresentou aderências classificadas como grau 2, ou seja, todas as aderências encontradas envolveram parede abdominal, inclusive aquelas de grau 1. Nenhum animal apresentou aderências de grau 5 (fístulas entéricas).

As estruturas envolvidas nas aderências peritoniais com a parede abdominal estão descritas na Tabela 4.

TABELA 4 - Estruturas envolvidas nas aderências peritoniais com a parede abdominal

\begin{tabular}{lcccc}
\hline & Grupo I & Grupo II & Grupo III & TOTAL \\
\hline Omento & 4 & 1 & 5 & 10 \\
Alças intestinais, omento e/ou & 0 & 10 & 1 & 11 \\
outros órgãos abdominais & 0 & 0 & 3 & 3 \\
Apenas alças intestinais & 7 & 0 & 1 & 8 \\
Ausência de aderências & 11 & 11 & 10 & 32 \\
\hline TOTAL & &
\end{tabular}

Verifica-se que 14 animais tiveram aderências peritoniais envolvendo alças intestinais, sendo todos animais com fixação da tela de polipropileno (grupos II e III). A análise desses dados pelo teste do qui-quadrado, comparando-se a incidência de aderências entre os animais nos quais não foi fixada tela de polipropileno (grupo I) e aqueles nos quais foi fixada a tela (grupos II e III), mostrou um $\chi^{2}(3,84)=13,34(P<0,05)$.

$\mathrm{O}$ número de pontos de aderências peritoniais entre alças intestinais e parede abdominal, foi menor no grupo III, como se pode ver na Tabela 5 .

TABELA 5 - Número de pontos de aderências peritoniais entre alças intestinais e parede abdominal

\begin{tabular}{lcccc}
\hline & Grupo I & Grupo II & Grupo III & TOTAL \\
\hline 1 ponto & 0 & 1 & 3 & 4 \\
Mais de 1 ponto & 0 & 9 & 1 & 10 \\
\hline TOTAL & 0 & 10 & 4 & 14 \\
\hline
\end{tabular}

Comparando-se esses resultados pelo teste do qui-quadrado, encontra-se $\chi^{2}(5,99)=9,96(P<0,05)$.

Um animal do grupo II apresentou evisceração no $5^{\circ}$ dia de pósoperatório. Nenhum animal apresentou obstrução intestinal com parada na eliminação de fezes.

\section{DISCUSSÃO}

Os pesos dos amimais no pré e pós-operatório (Tabelas 1,2) foram avaliados objetivando-se o uso de amostras semelhantes nos grupos. Pela análise da variância, verificou-se que os animais dos três grupos tinham pesos médios semelhantes, sem diferença estatística significativa tanto no pré-operatório, quanto por época da necropsia.

Pelo teste $t$ avaliou-se se havia diferença estatística nos pesos dos animais antes e depois do experimento, hipótese que foi refutada. Assim, pôde-se inferir que os animais foram submetidos as mesmas condições ambientais durante todo o experimento, sem fatores que os levassem a alterações significativas do metabolismo, refletidas como ganho ou perda excessiva de peso.

Como a cada dia de experimento foram realizados procedimentos em números iguais de animais de cada grupo e necropsias em animais que foram operados num mesmo dia, a média de tempo entre os dois procedimentos para cada grupo foi igual.

Estudos em humanos demonstram que aderências peritoniais ocorrem em mais de $90 \%$ dos pacientes submetidos a grandes cirurgias abdominais e em $55 \%$ a $100 \%$ daqueles submetidos a cirurgias pélvicas ${ }^{(15)}$. No presente estudo experimental, as aderências peritoniais estiveram presentes na maioria dos casos $(75 \%$ dos animais), conforme a Tabela 3. 
Ainda na Tabela 3, observa-se que dos animais que não apresentaram aderências peritoniais, a maior parte $(87,5 \%)$ pertencia ao grupo I. Já dos que apresentaram aderências, a maioria pertencia aos grupos II ou III. Analisando-se esses dados pelo teste do qüiquadrado, verificou-se que na vigência da tela de polipropileno, os animais apresentaram significativamente mais aderências do que na sua ausência. Isto é apoiado por estudos que mostram que a tela de polipropileno, quando exposta aos órgãos intra-abdominais, associa-se a maior número de aderências ${ }^{(4)}$.

Verifica-se, também pela tabela 3, que todos animais do grupo II e a maioria do grupo III (90\%) apresentaram aderências peritoniais. Avaliando-se esses dados pelo teste do qüi-quadrado, observou-se que a tela embebida com nitrofurazona não reduziu significativamente a incidência de aderências quando comparada à tela sem nitrofurazona.

Levando-se em consideração a classificação por intensidade de aderência proposta pela metodologia, verificou-se que nos grupos II e III houve predomínio de aderências classificadas como graus 3 e 4 (Tabela 3). Entre os animais do grupo II, a maior parte teve aderências de grau 4. Já no grupo III, a maioria apresentou aderências de grau 3, sendo que neste grupo um animal não apresentou aderências. Avaliando-se esses valores pelo teste do qüi-quadrado, conclui-se que os animais submetidos a fixação de tela de polipropileno associada à nitrofurazona tiveram aderências menos intensas do que aqueles animais tratados com tela de polipropileno sem nitrofurazona. Esse fato poderia ser explicado pela ação da nitrofurazona diminuindo o tecido de granulação, o que interfere nas aderências abdominais, já que estas estão relacionadas a defeitos no processo de cicatrização ${ }^{(12,25)}$.

A Tabela 3 mostra, também, que todas as aderências encontradas nos grupos II e III envolveram parede abdominal, o que comprovaria o aumento das aderências promovido pelo contato com a tela e justificaria a menor intensidade das aderências no grupo III, já que a nitrofurazona reduz o tempo do processo inflamatório, deixando que somente o preenchimento das irregularidades da superfície da tela pelo tecido adiposo aja nesse mecanismo ${ }^{(4,26)}$.
Segundo critérios de qualificação e quantificação de aderências peritoniais, baseados nos estudos de MORENO-EGEA et al. ${ }^{(19)}$, aquelas que envolvem somente tecido adiposo são menos graves do que aquelas que envolvem alças intestinais, visto que estas constituem a causa mais comum de suboclusão, obstrução mecânica e estrangulamento intestinal ${ }^{(9)}$. Todas as aderências encontradas nos animais do grupo I envolveram apenas tecido adiposo (omento) e nos grupos II e III, 14 animais tiveram aderências envolvendo alças intestinais (Tabela 4). Pode-se concluir que os animais submetidos a fixação de tela tiveram aderências mais graves.

Ainda conforme esses critérios, a gravidade do processo adesivo é proporcional ao número de pontos de aderência ${ }^{(9)}$. Na Tabela 5, verificou-se uma preponderância no grupo II, sendo que neste, a maioria apresentou aderências envolvendo as alças intestinais em mais de um ponto. Já no grupo III, os animais que tiveram aderências entre alças intestinais e o peritônio parietal, o foram em apenas um ponto. A avaliação estatística pelo método do qüi-quadrado mostrou diferença significativa entre os grupos II e III, mostrando que no II o processo foi mais grave.

Um animal do grupo II apresentou evisceração, fato incomum na aplicação de telas de polipropileno, já que estas possuem força tênsil satisfatória para se evitar isso, ocorrendo geralmente por defeitos técnicos na sua fixação ${ }^{(17)}$. Atribuiu-se a isso o arrancamento precoce do curativo pelo animal, com destruição parcial da tela.

\section{CONCLUSÃO}

Em animais de experimentação o uso de tela de polipropileno associada à nitrofurazona não diminuiu as aderências entre as alças intestinais e o peritônio parietal. Essa associação, porém, permitiu que estas ocorressem em menor intensidade e, portanto, em menor gravidade.

\section{AGRADECIMENTO}

À Fundação de Amparo à Pesquisa do Estado de Minas Gerais (FAPEMIG), pelo fomento deste projeto de pesquisa.

Diogo-Filho A, Lazarini BCM, Vieira-Junyor F, Silva GJ, Gomes HL. Evaluation of postoperative adhesions in rats submitted to peritoneostomy with polypropylene mesh associated to nitrofurazone. Arq Gastroenterol 2004;41(4):245-9.

ABSTRACT - Background - Peritoneal injuries, common in per and postoperative, lead to the formation of adhesions. The use of polypropylene mesh increases the postoperative adhesions incidence. Based on the fact of nitrofurazone accelerates the healing process, a possible action on peritoneal adhesions was cogitated. Aim - To evaluate postoperative adhesions in rats submitted to peritoneostomy with polypropylene mesh fixation associated to nitrofurazone. Methods - Thirtythree Wistar rats were separated into three groups of eleven animals each one. In group I was performed the laparotomy with exposition of the abdominal cavity followed by the laparotomy suture; in group II was performed the resection of a abdominal wall fragment followed by polypropylene mesh fixation on the gap and in group III was performed the same done in group II, but the mesh was previously impregnated with nitrofurazone. After 45 days the animals were sacrificed and necropsied. Results - Seven animals of group I had no adhesions (degree 0), two had degree 1 adhesions and two had degree 2. In group II, one animal was classificated as degree 3 and ten as degree 4 . In group III, one had degree 0, eight had degree 3 and one had degree 4 (one animal died before 45 days). All adhesions found involved the abdominal wall; ten animals had adhesions involving only omentum (group I = 4; group II = 1 and group III = 5); eleven animals had adhesions involving omentum, small bowel and other abdominal organs (group II $=10$; group III $=1$ ); three animals had adhesions involving only small bowel, all belonged to group III. Fourteen animals had adhesions involving small bowel, of these ten belonged to group II (nine with more than one fixation point) and four belonged to group III (three with just one fixation point). Conclusion - The association of nitrofurazone with polypropylene mesh did not reduce significantly the postoperative adhesions incidence in rats, but reduced the intensity and severity of these adhesions.

HEADINGS - Peritoneum, surgery. Adhesions. Surgical mesh. Nitrofurazone. Rats. 


\section{REFERÊNCIAS BIBLIOGRÁFICAS}

1. Assunção JV, Pesquero CR. Dioxinas e furanos: origens e riscos. Rev Saúde Pública 1999;33:523-30.

2. Avsar FM, Sahin M, Aksoy F, Avsar AF, Akoz M, Hengirmen S, Bilici S. Effects of diphenhydramine $\mathrm{HCl}$ and methylprednisolone in the prevention of abdominal adhesions. Am J Surg 2001;181:512-5.

3. Bauer JJ, Harris MT, Gorfine SR, Kreel I. Rives-Stoppa procedure for repair of large incisional hernias: experience with 57 patients. Hern 2002;6:120-3.

4. Besim H, Yalcin Y, Hamamci O, Arslan K, Sonisik M, Korkmaz A, Erdogan S Prevention of intraabdominal adhesions produced by polypropylene mesh. Eur Surg Res 2002;34:239-43.

5. Bevilacqua RG, Soares LA, Melo Jr FF. Cirurgia das hérnias umbilicais e incisionais In: Goffi FS, editor. Técnica cirúrgica: bases anatômicas, fisiopatológicas e técnicas de cirurgia. São Paulo: Atheneu; 1997. p.491-8.

6. Boey JH. Cavidade peritoneal. Aderências peritoneais. In: Way LW, editor. Cirurgia: diagnóstico e tratamento. Rio de Janeiro: Guanabara Koogan; 1994. p.331.

7. Clark JD, editor. Guide for the care and use of laboratory animals. Washington D.C. Institute of Laboratory Animal Research, Commission on Life Sciences, National Research Council. National Academy Press; 1996.

8. Dinsmore RC, Calton WC, Harvey SB, Blaney MW. Prevention of adhesions to polyproylene mesh in a traumatized bowel model. J Am Coll Surg 2000;191:131-6.

9. D'Oliveira DMR, Nigro AJT, Fagundes DJ, Novo NF, Juliano Y, Pimenta ALP. Estudo morfológico de aderências peritoneais induzidas pela rifamicina em ratos. Acta Cir Bras 2001;16:110-1

10. Fuzun M, Kaymak E, Harmancioglu O,Astarcioglu K. Principal causes of mechanical bowe obstruction in surgically treated adults in Western Turkey. Br J Surg 1991;78:202-3.

11. Jesus-Carlos P, Miranda ML, Gândara LFP, Guimarães-Filho MAC, Mathias I, Marques RG. Utilização de membrana de sódio- hialuronidase/carboximetil-celulose na prevenção de aderências intra-abdominais em ratos. Acta Cir Bras 2001;16(Supl 1):110-1.

12. Johnson JR, Delavari P, Azar M. Activities of a nitrofurazone containing urinary catheter and a silver hydrogel catheter against multidrug-resistant bacteria characteristic of catheter associated urinary tract infection. Antimicrob Agents Chemother 1999;43:2990-5.

13. Kluger Y, Weinbroum A, Ben-Avraham R, Galili Y, Klausner J, Rabau M. Reduction in formation of peritoneal adhesions by methylene blue in rats: a dose response study. Eur J Surg 2000;166:568-71.

14. Kramer K, Senninger N, Herbst H, Probst W. Effective prevention of adhesions with hyaluronate. Arch Surg 2002; 137:278-82.

15. Liakakos T, Thomakos N, Fine PM, Dervenis C, Young RL. Peritoneal adhesions: etiology, pathophysiology and clinical significance. Recent advances in prevention and management. Dig Surg 2001;18:260-73.
16. Lopes-Filho R, Silva AL. Padronização das técnicas operatórias de autonomização no retalho musculocutâneo transverso do músculo reto do abdome monopediculado. Acta Cir Bras 2002;17:236-41.

17. Mazzini DL, Mantovani IM. Fechamento da parede abdominal com afastamento parcial das bordas da aponeurose utilizando sobreposição com telas de vicryl e marlex em ratos. Acta Cir Bras 1999;14:28-34.

18. Miranda ML, Jesus-Carlos P, Vaitsman GP, Leal AP, Mathias I, Marques RG. Prevenção de aderências entre órgãos intra-abdominais e tela sintética em rato com utilização de membrana de sódio-hialuronidase/carboximetil-celulose. Acta Cir Bras 2001; $16: 111$

19. Moreno-Egea A, Aguayo JL, Zambudio G, Parrila P. Influence of different aetiological agents in formation of postoperative adhesions: experimental study in rats. Dig Surg 1993; 10:101-5

20. Oliveira N, Paschoa AF, Crespo CC, Massumoto CM, Adam C. Utilização do derivado da nitrofurazona com o polietileno-glicol (NPG)+ para prevenção da formação de aderências peritoneais: estudo experimental. Arq Gastroenterol 1981;18:54-9.

21. Poli-de-Figueiredo LF, Borges LA, Rasslan S. Tratamento - Terapia cirúrgica. In: Consenso Brasileiro de Sepse. São Paulo: Hospital Albert Einstein/AMIB; 2003. p.9.

22. Poupée JC, De Saint-Julien J, Le Saint B, Hamon M, Flandrin P. Traitment des infections en chirurgie générale par la rifamycine s.v. utilisée par voie locale. LMM Med Sud-est 1981;12:4658-61.

23. Singh SK, Chakravarty S. Effect of nitrofurazone on the reproductive organs in adult mice. Asian J Androl 2001;3:39-44.

24. Takegawa K, Mitsumori K, Yasuhara K, Moriyasu M, Sakamori M, Onodera H, Hirose $\mathrm{M}$, Nomura T. A mechanistic study of ovarian carcinogenesis induced by nitrofurazone using ras $\mathrm{H} 2$ mice. Toxicol Pathol 2000;28:649-55.

25. Treutner KH, Schumpelick V. Prevention of adhesions: wish and reality. Chirurg 2000;71:510-7.

26. Vavrik J, Foltynova V, Vitkova I, Adamek S, Pouckova P. Changes in abdominal wall after mesh implantation in rats. Med Sci Monit 2000;6:476-9.

27. Vrijland WW, Bonthuis F, Steyerberg EW, Marquet RL, Jeekel J, Bonjer HJ. Peritonea adhesions to prosthetic materials: choice of mesh for incisional hernia repair. Surg Endosc 2000;14:960-3.

28. Xu X, Pappo O, Garbuzenko E, Bischoff SC, Rivkind A, Levi-Schaffer F. Mast cell dynamics and involvment in the development of peritoneal adhesions in rat. Life Sci 2002;70:951-67. 